\title{
INTEGRATED AUTOMATION SYSTEM OF MINERALS PROCESSING AND ITS APPLICATIONS
}

\author{
Tianyou Chai*, Jinliang Ding, Dayong Zhao, Aijun Yan
}

Research Center of Automation, Northeastern University, Shenyang, P.R.China 110004

\begin{abstract}
The integrated automation system consisting of production process management system, optimal system of production indices and process control system is established for the optimization of production indices of minerals processing. The structure and functions of this system are discussed. The optimal control strategy for production indices is proposed to transform the target of production indices into the optimal setpoints of process control system automatically. It has been applied successfully to the largest hematite minerals processing factory of China with significantly proven benefits. Industrial applications show the good performance of the suggested system and its bright future in the industry. Copyright (C) 2005 IFAC
\end{abstract}

Keywords: Process automation; Management system; Optimal systems; System integration; Indices; Control engineering; Control applications

\section{INTRODUCTION}

Great progress has been made by the metallurgical industries of China, such as iron and steel, aluminium, etc. In fact, China has become one of the largest producers in the world on metallurgical products. Minerals processing is an important basis of the metallurgical industry. Despite the abundant mineral resources in China, mining, minerals processing and smelting are difficult due to lower tenor of minerals. At present, there are thousands of minerals processing companies in China, where low automation level of minerals processing has led to high production cost, large expenditure of resources and serious environmental pollution. These form the bottleneck nature in the development of the metallurgical industry in China. In this context, the integrated automation system in process industries is the key to solve these problems. In general, the control system of minerals processing consisting of three layers: process stabilization, process optimization and process management as developed by Houseman, et al. (2001). An example is the fivelayered computer integrated process system as proposed by Williams, which consists of process control, process optimization, production scheduling,

*Corresponding author. Tel:+86-24-23909158 Fax:+8624-23895647.Email: Tychai@mail.neu.edu.cn (T.Y. Chai). enterprise management and economic decision. Moreover, the integrated automation system with three layers, namely the Enterprise Resource Planning (ERP), Manufacturing Execution System (MES) and Process Control System (PCS), has been successfully applied to Paishanlou Gold Mine of China (Chai, et ,al, 2003). Such system has been shown to provide many benefits to this gold mine.

Industrial process control requires not only the accuracy of control loops but also an optimal control of production performance indices related to product quality, production efficiency and cost. Charbonnier et al. (1999) has pointed out that reduction of production cost, improvement of product quality, minimization of environmental pollution and the minimization of resource consumption can only be achieved by an optimum design of all automatic control facilities. Integrated optimal control method adopting local control loops and the higher supervisory control for optimal control of technical indices is proposed for complex metallurgical processes by Chai and Guan, et al.(1998), and Guan, et al.(2001). Optimal control of economic indices of chemical processes has been developed by Lu (1997), Skogestad (2000), Robinson, et al.(2001), and Lu, (2003) through the use of model predictive control and steady state optimization. Since optimal control of production indices involves both the management 


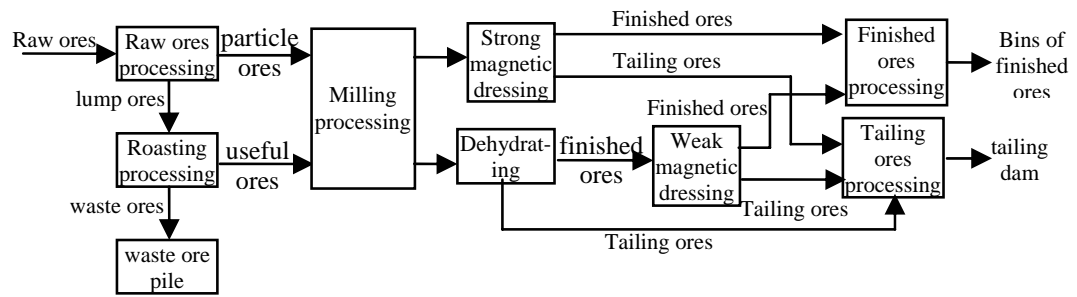

Fig. 1. Flow chart of iron minerals processing

and the control of production processes and the production indices are hard difficult to be measured on-line, it is an urgent and difficult problem yet to be solved for industries.

In this paper, the proposed new integrated automation system of minerals processing can realize the optimization of production indices and has been applied successfully to a minerals processing factory of China. It has been proven to be capable of providing many benefits to this factory.

\section{DESCRIPTION OF MINERALS PROCESSING}

As shown in Fig. 1, the minerals processing of hematite ore includes raw ore processing, roasting, milling, dehydrating, magnetic dressing, finished ores processing and tailing ore processing. The purpose of the raw ore processing is to sift raw ores to particle ores of $0-15 \mathrm{~mm}$ in size and lump ores larger than $15 \mathrm{~mm}$ in size. The particle ores are then sent to the cylinder bin of strong magnetic ores as the feed material to the strong magnetic ore processing. The lump ores are then stored in the stock bins as the feed material to the roaster.

The roasting process is used to heat lump ores in the shaft roaster. The roasted ores are separated magnetically into waste ores and useful ores. The waste ores are transported to the waste ore pile, and useful ores are sent to the cylinder bin of weak magnetic ores as the feed material to the milling processing.

The milling process consists of two sections of milling. The first section of the milling system forms a closed loop with the ball mill and the grader. The second section of the milling system forms a closed loop with ball mill and hydraulic swirler. The strong magnetic ores or weak magnetic ores are then sent to the ball mill for milling, and graded afterwards. The sand return is sent back to the ball mill for remilling and the overflow of grader enters the swirler. The depositing sand of the swirler enters the secondary ball mill for remilling. The overflow of swirler goes through the magnetic dressing process. Then the finished ores and tailing ores enter the processing system. After processing they are sent into the bins and the tailing dam respectively.

\section{INTEGRATED AUTOMATION SYSTEM FOR OPTIMIZATION OF PRODUCTION INDICES}

\subsection{System structure and functions}

The integrated automation system of minerals processing is composed of the production process management system, the optimal system of production indices, the process control system and the computer support systems as shown in Fig.2. Different from the standard framework, a new function block, namely the production indices optimal system, has been included, which performs the transformation of the production indices into a group of optimal setpoints. The computer support system consists of the relational database, real-time database and computer network system. The integration of the production process management system, the optimal system of production indices and the process control system with the help of the computer network and database ensures the optimal control over production indices.

Production process management system of minerals processing has the following subsystems: production plan, production scheduling, quality management, production cost control, energy management, equipment management, material management, viewing and decision support, and statistic and analysis

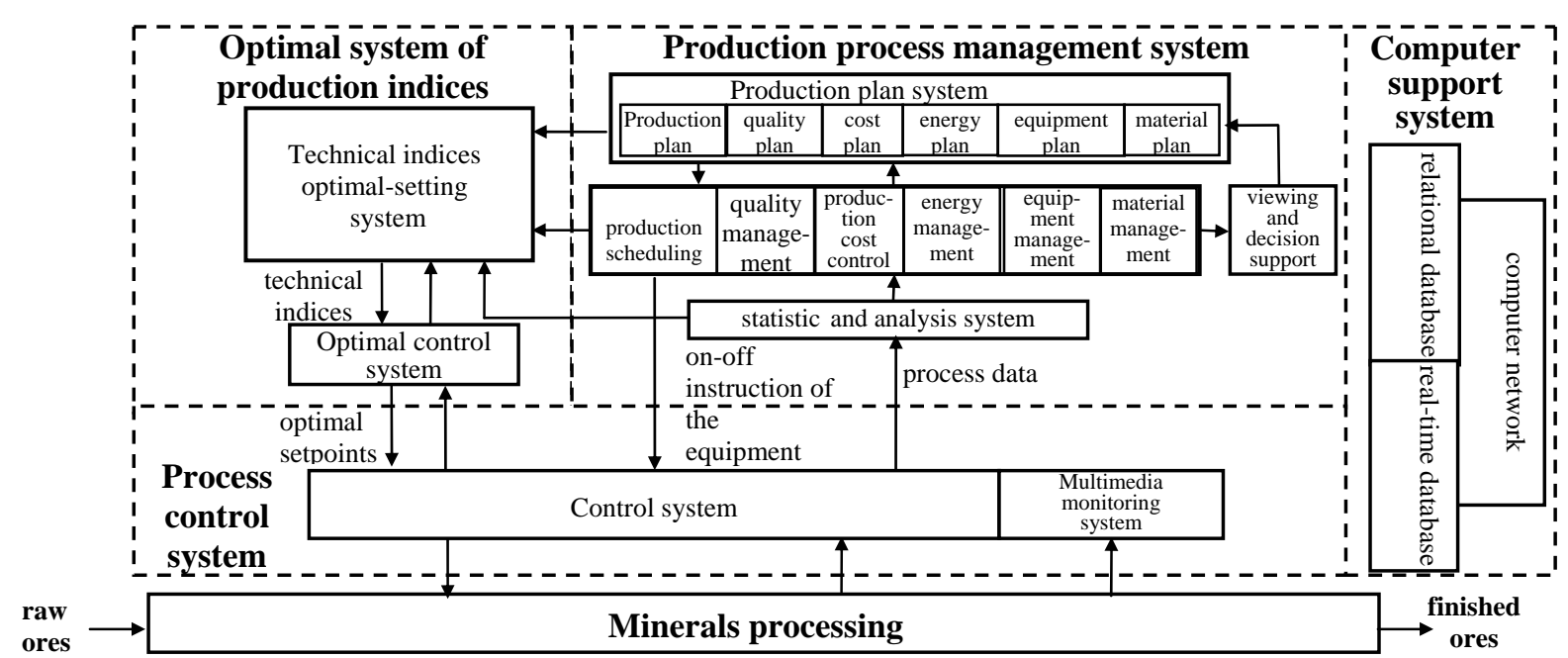

Fig.2 Structure of the integrated automation system for optimization of production 
system. The production plan system generates production plan, quality plan, cost plan, energy plan, equipment plan and material plan for minerals process. Then the production scheduling performs a real-time scheduling according to the production plan. Statistic and analysis system acquires the process data through the control system, and offers information to the subsystems of production scheduling, quality management, production cost control, energy management, equipment management and material management, and collects and analyses the data of production conditions. This process guarantees the completion operation of the plans. The production cost, material consumption and energy consumption of minerals processing are controlled according to the plans of cost, material consumption and energy consumption. The operation of equipment and the maintenance of equipment are managed to guarantee the safe operation of the equipment. Quality control in the factory has been performed through the quality data assessments from an on-site laboratory. These quality data play a key role in assessing the efficiency of the concerned production. Through the collection of laboratory data of ore materials, ore pulp, and material feed, the realtime management and control of product quality are carried out. Viewing and decision support system offers the information to help the operators to adjust the plan according to the data on quality, cost, energy, equipment and material, etc.

The optimal system of production indices consists of the technical indices optimal-setting system and the optimal control system of the technical indices. Such unit is used to automatically transform the target of production indices into the optimal setpoints of process control systems. The production indices of minerals processing are tenor of finished ores, recovery rate of metals, quantity of ore processing and cost of finished ores. Firstly, the technical indices optimal-setting system transforms the target of the production indices automatically into the optimal technical indices, which are the recovery rate of magnetic tube of roaster and granularity of ore pulp of ball mill. Then the optimal technical indices were transformed into a group of optimal setpoints of process control system by the optimal control system that realizes the optimal control of technical indices in the dynamic environment.

The process control system consists of the control system and the multimedia monitoring system. The former is used to implement the start, stop, interlocking and fault handling of production equipments, and the closed loop control of process parameters such as the temperature of combustion chamber, negative pressure, flow of gas and air in the roasting process, and ore feed pressure of swirler, ore feed, density of ore pulp, liquid level, material level, flow of water feed to the mill, ore feed to swirler in the milling process, etc. The multimedia monitoring system monitors raw ore processing, roasting, milling, dressing, dehydrating, and the operating states of the equipment, and produces trend curves in real time of key process parameters on-line.

\subsection{Intelligent optimal control strategy}

In practice, the production indices are closely related to technical indices, which are determined by the setpoints of the process control system. Qualitatively, the production indices optimal control problem is to produce the optimal setpoints of the control system so that the real production indices fall within the target range of production indices.

Since minerals processes are of a complex nature (e.g. high nonlinearity, serious coupling, time varying and without mathematics model), and production indices and technical indices cannot be continuously measured on-line, the production indices optimal control cannot be achieved using the well-known conventional optimal control methods. The twolayered optimal system of production indices including the optimal-setting level and the control level of technical indices is proposed in this paper as shown in Fig. 3 and Fig. 4. This optimal system is described in the following.

The technical indices optimal-setting system is actually a prediction/feedback adjusting system with an optimal decomposition model of the production indices, which is outlined as follows and also illustrated in Fig. 3:

1) a production indices optimal decomposition model is used to transform production indices into the technical indices.

2) a prediction adjusting system is employed to predict the production indices adopting prediction model of production indices and adjust the technical indices with the help of predicting analysis.

3) a feedback adjusting system is utilized to calculate the production indices from the statistical process control (SPC) output and the related process data of minerals processing, and to regulate the technical indices with the help of feedback analysis, which will be taken as the optimal technical indices of the optimal control system.

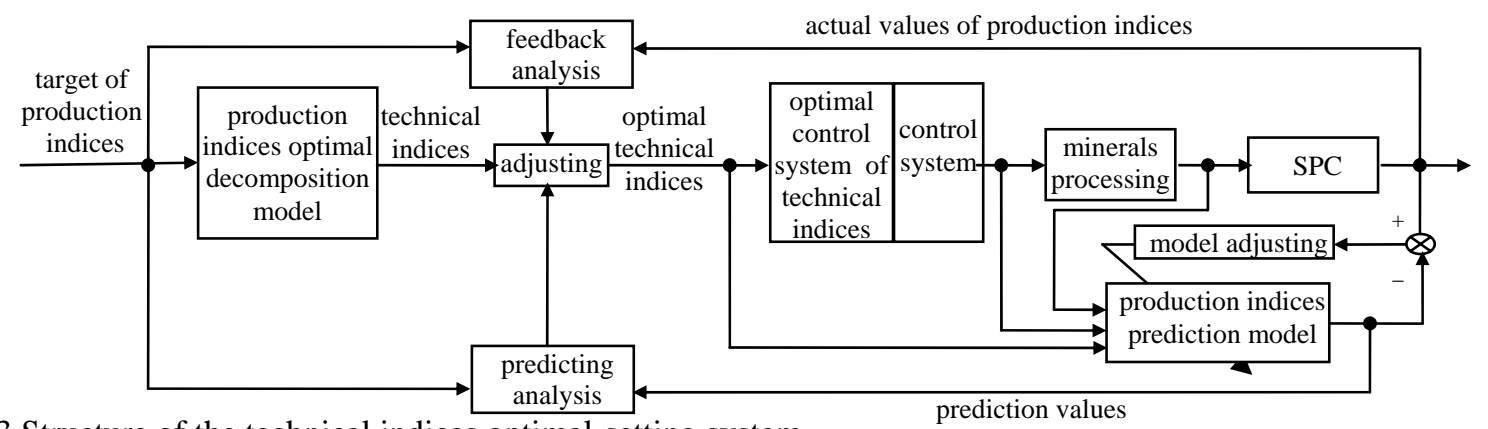

Fig.3 Structure of the technical indices optimal-setting system 


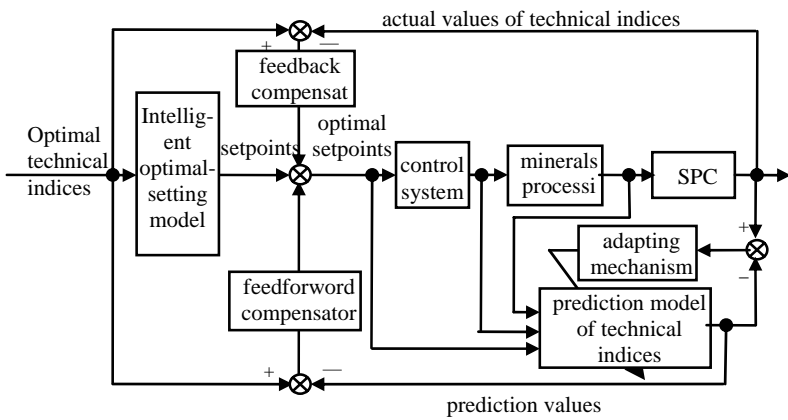

Fig.4 Structure of the optimal control system

The optimal control system of technical indices based on two levels of control of local loops and optimal-setting of these loops in Fig.4 is described in the following.

1) An intelligent optimal-setting model is used to transform technical indices into the setpoints of control loops of minerals processing.

2) A prediction model is used to predict the technical indices.

3) A feedforward compensator is employed to compare the optimal technical indices with prediction values of technical indices and compensates the effects of the variation in boundary condition according to the operating environment.

4) A feedback compensator is used to calculate the errors between the actual values from SPC and the optimal technical indices, and to produce setpoints compensation of control loops in order to minimize the above errors.

5) A SPC unit performs the human perception function to process the tested data from the on-site laboratory of technical indices.

6) A control system ensures the tracking of setpoints of control loops using the distributed control system(DCS), which is widely used in minerals processing.

\section{APPLICATION}

\subsection{Introduction of integrated automation system of a minerals processing factory}

A largest factory for hematite in China has an annual processing capability for five hundred million tons of iron ores, and the tenor of the hematite is thirty-three percent. The management and control of the main working procedures, such as the raw ores sieving, dry dressing and transportation of raw materials, roasting, milling, magnetic dressing, dehydrating and condensing were all handled by human operators which results in redundant personnel, low efficiency, high cost and high expenditure. Considering the actual situation of this minerals processing factory, the integrated automation system is built by adopting the proposed method.

The hardware structure of the system is shown in Fig.5. The ControlLogix system of Rockwell is used in the control system, where personal computers and Hewlett Packard LH3000 servers are used in the production indices optimal system and production process management system. The information integration of production process management system, production indices optimal system and process control system is achieved by using ControlNet, DeviceNet, Ethernet, real-time database and relational database. The integrated automation system is installed in the production command and control center, where the operators can manage the production process by the production process management system and control the production process by process control system and production indices optimal system on-line.

\subsection{Optimal system of production indices}

The main working procedures in this factory are roasting process and milling process. There are twenty-two roasters in the roasting procedure. Because of strong coupling between inputs and outputs of the roaster, complicated mechanism of ore move, the heat transfer, chemical reaction of the ore, and many uncertain factors such as the change of the characteristic of the ore, the variations are seen in the heating gas composition, hard measuring of recovery rate of magnetic dressing tube and the temperature of the reduction zone on-line. There are eight series of fifteen mills in the milling procedure. The milling process is characterized in terms of large time delays, strong coupling and serious non-linearity. The milling granularity of ore pulp and milling load cannot be accurately measured on-line. Therefore, it is difficult to apply the optimal control methods based on accurate mathematical models to roasting and milling process.

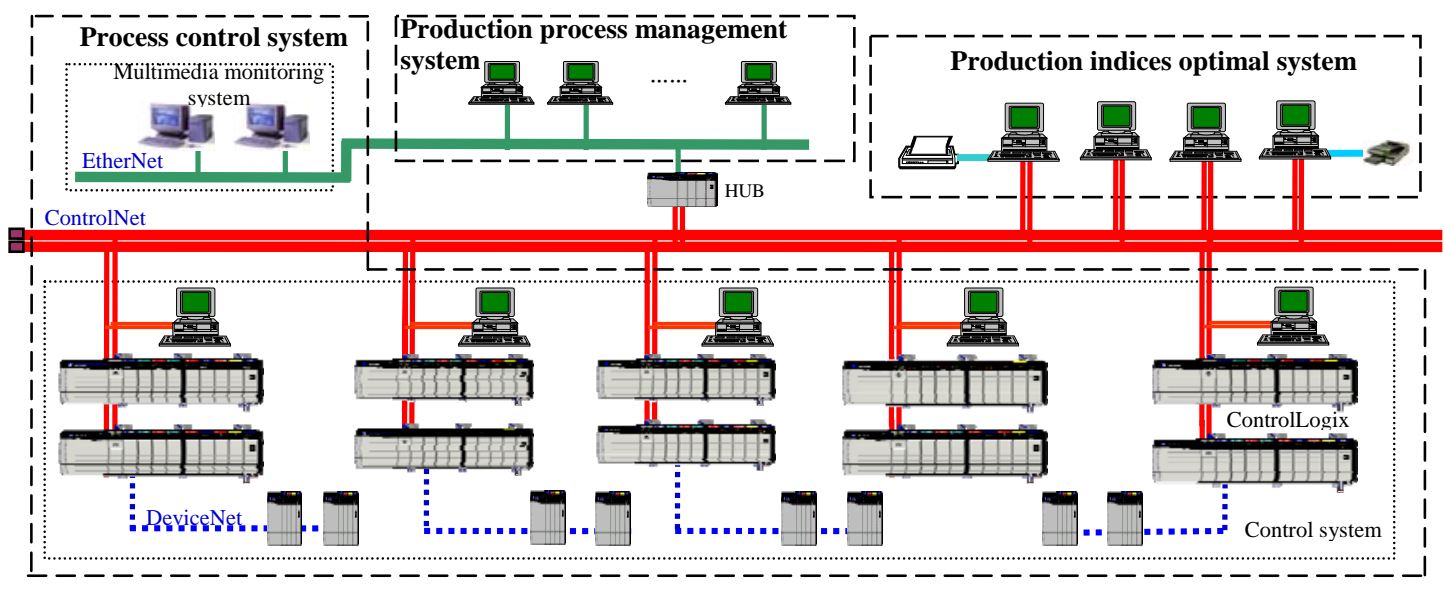

Fig. 5 The hardware structure of the integrated automation system 
The optimal system for the production indices of the roasting and milling process is constructed as shown in Fig.6 using the proposed control strategy. The major components of such a system consists of 1) the technical indices optimal-setting system, 2) the intelligent optimal-setting model, 3) the statistical process control (SPC) unit, 4) the predictors of $R$ and $G$, and 5) a feedforward compensator. Details are described below.

1) The technical indices optimal-setting system adopts a case-based reasoning to express the successful production management cases and knowledge with descriptors and solutions of cases. The case solutions are optimal magnetic tube recovery rate $R s$ and granularity of ore pulp $G s$ which are obtained by case retrieval, reuse, revision and retention methods (Tan and Chai, 2005). It can automatically transform the target of production indices, metal recovery rate $R m$ and tenor of finished ores $\mathrm{Tf}$, (quantity of ore processing Qo and cost of finished ores $C$ are taken as the constraints) into optimal technical indices Rs and Gs.

2) The intelligent optimal-setting model adopts casebased reasoning technique as well, which produces the proper setpoints of combustion chamber temperature $\mathrm{Te}$, reduction gas flow $\mathrm{Fe}$, move out time $T$ s, ore feed $Q$, overflow concentration $D_{1}$, and water feed $H$.

3) The SPC unit produces the mean values of each quality variables in the following way

$$
R=\sum_{i=1}^{K} R b(i) / K, G=\sum_{i=1}^{k} G b(i) / K,
$$

where $R b(i)$ and $G b(i)$ are tested data from the onsite laboratory, and $K$ is the sample number.

4) The predictors of $R$ and $G$ are realized via two BP neural network models, namely $N N 1$ and $N N 2$. The inputs to $N N 1$ are $\mathrm{Te}, \mathrm{Fe}$ and Ts whilst the output is the predicted value of $R$ as denoted by $R p$. The inputs to $N N 2$ are $Q, H, D_{1}$, the swirler feed concentration $D_{2}$ and feed pressure $P$ whilst the output represents the predicted value of $G$ as denoted by $G p$. The supervisory signals for the training algorithm are given by

$e_{r}(k)=R(k)-R p(k), e_{g}(k)=G(k)-G p(k)$. The conventional weighted RLS method is used as the learning algorithm of these neural network models, where the above supervisory signals are used to eliminate the prediction error by adaptively tuning the weights.

5) The feedforward compensator is given by

$N_{f}(k)=N_{f}(k-1)+\Delta N_{f}(k)$,

$\Delta N_{f}(k)=K_{f p} \Delta e_{f}(k)+K_{f l} e_{f}(k)$,

$\Delta e_{f}(k)=e_{f}(k)-e_{f}(k-1), e_{f}(k)=\left[e_{f 1}(k), e_{f 2}(k)\right]$, where $N_{f}$ represent the feedforward compensation of $R$ and $G$. Prediction errors of $R$ and $G$ is expressed as

$e_{f 1}(k)=R s(k)-R p(k), e_{f 2}(k)=G s(k)-G p(k)$, where $G p(k)$ and $G p(k)$ is predications of $R$ and $G$. Feedback compensator is given by

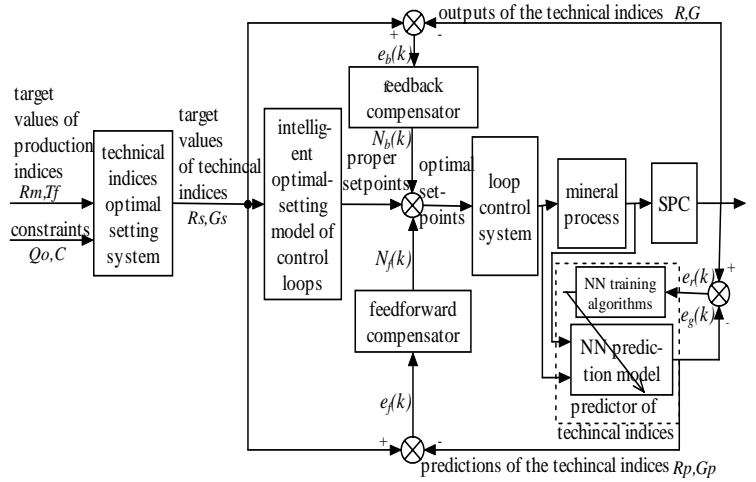

Fig.6 Optimal system of roasting and milling process

$\Delta e_{b}(k)=e_{b}(k)-e_{b}(k-1), e_{b}(k)=\left[e_{b 1}(k), e_{b 2}(k)\right]$, where $N_{b}$ represent the feedback compensation of $R$ and $G$. Feedback errors of $R$ and $G$ are $e_{b 1}(k)=R s(k)-R(k), e_{b 2}(k)=G s(k)-G(k)$. $K_{f p}, K_{f i}, K_{b p}, K_{b i}$ represent the proportional and integral parameters of feed forward and feedback PI controller respectively and determined by simulations and industrial experiments.

\subsection{Application results}

In this minerals processing factory, the targets of the production indices are

$R m \geq 76 \%, 52.2 \% \leq T f \leq 52.8 \%$.

The technical indices optimal-setting system produces the optimal technical indices given by

$79.5 \% \leq R s \leq 82.5 \%, 75 \% \leq$ Gs $\leq 81 \%$.

Operating results of optimal control systems from Nov. 25 to 28, 2003 are as follows. The real control curves of the roasting process are shown in Fig. 7. From Fig. 7 it can be seen that the outputs of combustion chamber temperature and move out time ( $T r$ and $T s$ ) can track the setpoints very well, and output of reduction gas flow $(\mathrm{Fr})$ cannot track the setpoint because the reduction gas pressure $\mathrm{Pr}$ is too low. However, from Fig. 8 it can be seen that the magnetic tube recovery rate falls within target range of the optimal technical indices despite big tracking errors of reduction gas flow. Long-term operation

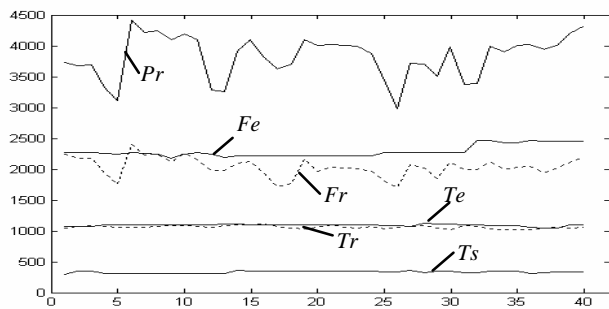

Fig. 7. Setpoint responses and the related closed loop outputs of the roasting process

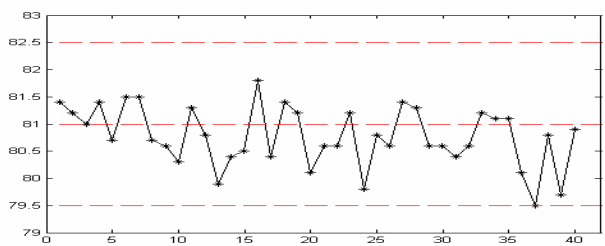

Fig. 8. Qaulity control result of magnetic tube recovery rate 


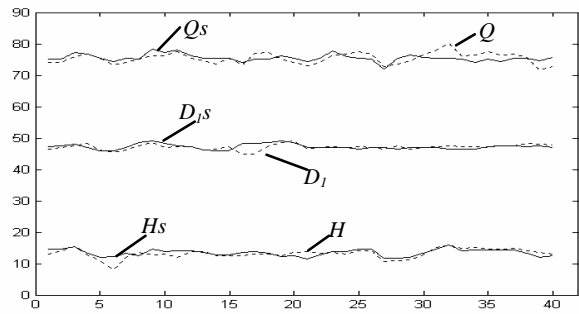

Fig.9. Setpoint responses and the related closed loop outputs of the milling process

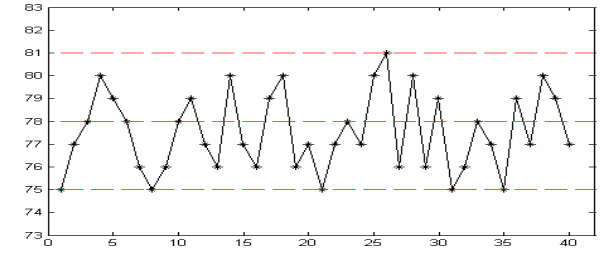

Fig.10. Qaulity control result of ore pulp granularity

results show a $2 \%$ improvement in magnetic tube recovery rate and a $0.72 \mathrm{~T} / \mathrm{h}$ increase in productivity of the shaft furnace.

The real control curves of the milling process are shown in Fig. 9. From Fig. 9 it can be seen that the outputs of ore feed, overflow concentration, and water feed $\left(Q, H\right.$ and $\left.D_{1}\right)$ can track their setpoints very well. From Fig. 10 it can see that the ore pulp granularity falls within target range of the optimal technical indices. Long-term operation result shows that a $3.76 \%$ increase in ore pulp granularity.

After 16 months of running of the proposed system, the statistical analysis shows that metal recovery rate $R m$ is increased to $76.01 \%$ from $74 \%$ with an improvement of $2.01 \%$. Tenor of finished ore is increased to $52.5 \%$ from $52 \%$ with an improvement of $0.5 \%$. Metal recovery rate and tenor of finished ores falls within target range. Furthermore, the successful application of the integrated automation system with 120 thousand tons improvement in raw ore processing capability every year, 2.98 percent improvement in the equipment operation rate, 50 percent reduction in operating personnel, 20 percent reduction in consumption, and 7.254 million kWH electricity saving every year. Because of above reasons, the proposed system has been shown to provide high economic benefit of more than 50 million RMB to this factory.

\section{CONCLUSIONS}

Process control systems and production process management systems have been widely used in the minerals processing industry. Although these systems can maintain a stable production, it is still a difficult and crucial task for industrial processes to achieve optimization of production indices. This paper has proposed an integrated automation system for minerals processing industry. The new system consists of production process management system, optimal system of production indices and process control system. The suggested system transforms the production indices into a group of optimal loop setpoints automatically in the dynamic environment with the help of the optimal system of production indices, which realizes optimization of production indices without using accurate mathematical models. The successful industrial application shows that this system has not only been proven to provide an improvement of recovery rate of metals, tenor of finished ores, equipments operation and reduction of resources expenditure and operators in minerals processing industry, but also has good application prospects in industrial processes.

\section{ACKNOWLEDGMENT}

This work is supported by the National Key Basic R\&D Program under Grant 2002CB312201 and the National Hi-Tech Development Program under Grand 2004AA412030 of China. (For papers by Chai, et, al, please refer to http://www.a-center.neu.edu.cn.)

\section{REFERENCES}

Chai, T.Y., et al (2003). Contemporary Integrated Manufacturing System Based on ERP/MES/PCS in Gold Mine Enterprise. Control Engineering of China, 10, pp.18-22.

Chai, T.Y. and S.P.Guan (1998). Object-oriented Integrated Control Technology of Complex Industrial Processes, Plenary Lecture, Proceedings of 5th Symposium on Low Cost Automation

Charbonnier, J.C., et al (1999). Technology Road Map to Determine the Research Priorities of the European Steel Industry. EUROFER.

Guan, S.P., H.X.Li and S.K.Tso (2001). Multivariable Fuzzy Supervisory Control for the Laminar Cooling Process of Hot Rolled Slab. IEEE TRANS CONTR SYST TECHNOL, 9, pp.348-356, MARCH.

Houseman, L.A., J.H. Schubert, J.R. Hart and W.D. Carew. (2001). PlantStar 2000: a plantwide control platform for minerals processing. Minerals Engineering. 14, pp.593-600.

Lu, Y.Z., M.He and C.W.Xu (1997). Fuzzy modeling and expert optimization control for industrial process. IEEE Trans. Contr. Syst. Technol. 5, pp. 2-12.

Lu, Z.J. (2003). Challenging control problems and emerging technologies in enterprise optimization. Control Engineering Practice, 11, pp.847-858.

Robinson, D., R.Chen, M.Thomas, and P.D. Schnelle (2001). An optimal control based approach to designing plantwide control system architectures. Journal of Process Control, 11,pp.223-236.

Skogestad, Sigurd (2000). Self-optimizing control: the missing link between steady-state optimization and control. Computers and Chemical Engineering, 24, pp. 569-575.

Tan, M.H., and T.Y. Chai (2005). Modeling of the laminar cooling process with case-based reasoning. Control theory and applications. 22(2). 